\title{
De la coseidad del hombre según Marx a la cosificación del sujeto en Lacan
}

Lucero María Mendoza Olguín ${ }^{1}$

\section{Introducción}

En el consumo de infinidad de objetos, ropa, calzado, autos último modelo, gadgets como celulares, tabletas, laptops, juegos de video, ¿qué se vende? Dice un eslogan: "Todo el poder que quieras. Todo el día", y entonces, ¿qué se compra?, ¿se vende el producto, se vende la idea, se compra el objeto? ¿Se convierte el sujeto al objeto?

El anuncio que publica una clínica de belleza/cirugía plástica, que tiene el eslogan "Encontramos el cuerpo perfecto en ti", acompañado de la imagen de una muñeca Barbie, ¿anuncia la posibilidad de un cuerpo perfecto?, ¿la posibilidad de un cuerpo sin fallas?, ¿de transformarse en muñeca?

La sociedad industrializada incorpora esclavos a esas enormes empresas productoras de excesos: generar demanda $=$ más producto $=$ más dinero, jornadas de trabajo de 12 horas diarias, trabajos monótonos e inhumanos, que justo hacen del

1 Universidad Autónoma de Aguascalientes. 
sujeto una máquina más en las grandes bodegas de productos. Así lo exponen algunos compositores:

"Después de ocho horas de andar laborando desesperanza se siente en el hogar, pues con la friega que hay a diario ya no alcanza pa' progresar".

"La carencia", Panteón Rococó México

\author{
"Trabajo de esclavos no remunerado \\ me tienen pelando papas \\ y no pruebo la tortilla".
}

\title{
"Por eso mato", Mala Rodríguez \\ España
}

Por otra parte, artistas como Tetsuya Ishida (1973-2005), de origen japonés, pinta en su arte a sujetos convertidos en máquinas, sillones, antenas, mingitorios, microscopios, aviones; a hombres sumidos en el consumismo; a niños con raíces frente a una computadora; pinta un celular incrustado en un rostro humano, hombres sirviendo de asfalto, pisoteados, enterrados.

Claramente el mundo se encuentra frente a la tendencia que va cosificando al sujeto y lo vemos expuesto de diferentes formas, en diferentes contextos.

El propósito de este ensayo es exponer un trabajo de reflexión desde una perspectiva psicoanalítica lacaniana, en relación con una situación de nuestra sociedad hipermoderna: la relación que los sujetos tienen con los objetos, con la forma de consumo, con la forma de producto, donde se implica la forma de producir y ocupar un lugar dentro de un mundo gobernado casi absolutamente por la economía política del capitalismo.

Lo anterior conduce a algunas interrogantes. Primero, quizás, habría que entender cómo es que esta forma de economía se va adueñando de la sociedad, para luego poder dar forma tra- 
tando de exponer qué está ocurriendo en la sociedad hipermoderna a partir de esta forma de economía que va trascendiendo la economía misma, y así adentrarnos en la siguiente pregunta: ¿A qué responde la vulnerabilidad del sujeto ante dicha presencia?, y entonces, ¿qué puede hacerse ante la presencia de una economía que está saturando la existencia del sujeto?

\section{Desarrollo}

Al respecto de la primera cuestión, nuestra sociedad como propiedad de la economía política del capitalismo, puedo decir que la respuesta ya la había esbozado Karl Marx en sus Manuscritos económicos-filosóficos de 1844 (Marx, 1968). Haciendo una crítica a esta economía política, Marx va abordando una teoría en la que descubre los alcances de esta particular forma de relación entre productor y consumidor, entre capital y trabajador, relaciones que van siempre unidas a cosas y aparecen como cosas. Esos alcances, como expone Marx en la "teoría de la enajenación", son devastadores: "La coseidad equivale a la autoconciencia (hombre) enajenada y la coseidad es puesta por esta enajenación". Esta enajenación es sólo consecuencia de una economía política deshumanizante, "a medida que se valoriza el mundo de las cosas se desvaloriza, en razón directa, el mundo de los hombres [...]" (Marx, 1968: 75). Claramente, entre mayor sea el valor que se les da a las cosas, mayor será la cosificación de lo humano; en tanto el hombre produce, se potencializa la enajenación de él mismo, porque además: "su trabajo se convierte en un objeto, como un objeto extraño, fuera de él [...] lo mismo sucede en la religión: cuanto más pone el hombre en Dios, tanto menos guarda en sí mismo [...] para el trabajador se muestra la exterioridad del trabajo en que éste no es suyo, sino de otro, que no le pertenece [...]" (Marx, 1968: 75).

Y por bárbaro que parezca, agresivo e incluso hasta absurdo, el capitalismo moderno hace gala de esta visión. "Para David Ricardo, en su libro (Rent of the Land): las naciones son sólo talleres de producción, el hombre es una máquina de con- 
sumir y producir, la vida humana un capital [...], las leyes económicas rigen ciegamente al mundo [...], los hombres no son nada, el producto todo" (Marx, 1968: 46).

Además, estas ideas van confluyendo con ideas de otros pensadores que influyen en esta economía política, como Jeremy Bentham (1965), que afirma: "Mi noción del hombre es la de un ser que anhela la felicidad [...]" (Bentham, 1965: 3); "los elementos de la felicidad son los placeres y exenciones del dolor: placeres individuales y exenciones de dolores individuales [...]" (Bentham, 1965: 19); es decir, el hombre responde bajo un principio de mayor felicidad o principio de utilidad donde va a buscar aquello que le sirva para satisfacer sus placeres, además, "en una comunidad política, el alcance o extensión de un placer es tan grande como el número de personas por quienes ha sido experimentado" (Bentham, 1965: 18), donde el arte de gobernar consiste en el mayor bienestar posible para el mayor número de personas.

Pero, pensando en otra de las interrogantes: ¿qué está ocurriendo en la sociedad hipermoderna a partir de esta forma de economía que va trascendiendo la economía misma? Así como lo expone Lacan: "La idea imaginaria del todo, tal como el cuerpo la proporciona, como algo que se sostiene en la buena forma de la satisfacción, en lo que, en el límite, constituye una esfera, siempre fue utilizada en la política, por el partido de los predicadores políticos" (1969-1970: 31). Existen aquellos que presentan esta idea de felicidad, de una totalidad alcanzable que se intenta reflejar en un nivel de perfección que evidentemente es imposible, pero que se vende como posible, esta idea va seduciendo al sujeto, envolviéndolo en la fantasía de encontrar un momento de felicidad absoluta.

De este modo, va quedando en manos de los bienes terrenales la felicidad, pues para estos economistas no es más que la satisfacción de placeres inmediatos y, como dice Freud en Más allá del principio del placer (1920-1922), existen en los sujetos "[...] tendencias que serían más originarias al principio de placer e independientes de él [...] que implican la repetición de impresiones displacenteras (Freud, 2006: 16 y 17)", dicho de otro modo, haciendo referencia a Lacan (1969-1970): "el camino hacia la 
muerte no es nada más que lo que llamamos el goce". El sujeto no va a detenerse ante la satisfacción de una necesidad, sino que justamente se verá impulsado a algo que va más allá del alcance del placer, lo que va llevando a su propia destrucción, y aquí es donde nos encontramos con la pulsión de muerte, pulsión cuyo fin siempre es la satisfacción que se refleja como saldo irreductible a cero, cero tensión, cero vida.

La satisfacción de placeres inmediatos, a su vez, va convirtiendo al sujeto en lo que los mismos economistas señalan: máquinas de consumir y producir, el sujeto se vuelve extraño ante su propia realidad, enajenado, extraño al trabajo, extraño a sus vínculos, extraño a su vida, actúa por y para Otro, al servicio de Otro, ese Otro que Lacan nombró Autre, el Otro con mayúscula que se posiciona como Amo, y que sin embargo ahora estaría alejándose de lo que, por concepto, encontramos en él, a sabiendas de aquel que deposita su deseo sobre otro, pues parecería que el otro sólo le va siendo útil como objeto-máquina. Así lo dice Lacan en el Seminario 17: El Reverso del Psicoanálisis (1969-1970): "El proletario puede calificarse con el término de desposeído [...] la explotación capitalista le frustra de su saber, volviéndolo inútil [...]", es decir, el trabajador, que más bien se vuelve un esclavo, ya no posee ese saber sobre su hacer, sino que ahora el saber sobre su hacer lo posee el amo, quien entonces lo ha desposeído de un saber y lo va dejando atado a un hacer automático tal como una máquina; sin embargo, en cierta medida, el amo a su vez queda en manos del esclavo, porque es ahora él quien tiene la facultad de completar al amo en su saber, "He aquí lo que constituye la verdadera estructura del discurso del amo. El esclavo sabe muchas cosas, pero lo que sabe más todavía es qué quiere el amo, aunque éste no lo sepa, lo que suele suceder, porque de otro modo no sería un amo. El esclavo lo sabe, y ésta es su función como esclavo. Por eso la cosa funciona [...] (Lacan, 1969-1970: 32)". Dicho de otro modo, lo que interesa al amo es que la cosa marche, el amo capitalista funciona a partir de que existe un otro esclavo asumiendo su "todo-saber" que le ratifica su posición de amo, el amo le quita al esclavo su saber hacer y luego lo sostiene para 
que le devuelva un saber de su querer, cargando así el esclavo con la demanda del amo, que poco a poco lo va colocando como aquel titán de la mitología griega (Atlas), condenado a sujetar las columnas sobre las que se apoyaba el cielo de los dioses. Esto lo va reduciendo a la cosa gozada que mantiene al amo gozador, es decir, encontrando en el esclavo su ser reducido a lo real, cosificándose, porque ahora lo que sustituye al esclavo antiguo son los productos donde el esclavo mismo es un producto tan consumible como los otros, dice Lacan (1969-1970).

Esta cosificación, como se muestra en los ejemplos, está puesta en el cuerpo, esto es: se tiene a partir de una economía política que transciende fronteras y encontramos a lo largo de todo el mundo un imperativo que se va globalizando, el imperativo de goce de este amo en la sociedad hipermoderna que ordena convertirse al objeto, ¿de qué modo? El amo capitalista, por un lado, promete un bienestar a partir del cuerpo, en el que la solución a todos los problemas radica en la transformación del cuerpo cárnico (sustancias que intoxican al organismo, medicamentos, cirugías), pero además, detrás de esta promesa se encuentra una exigencia: no resulta necesario sólo satisfacer las necesidades para el placer propio, sino que su estatuto sobrevalorado se encuentra en la perfección, he ahí la exigencia de tal creencia, el placer anunciando el servicio para el Otro, esclavo del Otro, ese Otro que mira, bajo el supuesto que debe encontrar el cuerpo que quiere mirar, y así el producto que quiere comprar, pues el sujeto va convirtiéndose en el producto del amo (del capital), va trabajando, va sirviendo, va esclavizándose, sacrificando su vida para el Otro, así como David Ricardo dice: el producto lo es todo, precisamente el sujeto intentando alcanzar ese todo se está mimetizando al producto, ya sea máquina que produce o máquina que consume.

\section{Conclusiones}

El resultado que existe a partir de que el sujeto queda reducido a la máquina, al objeto, a la cosa, es ese real como registro al que se refiere Lacan, donde se encuentra el goce, esa insistencia de 
la pulsión de muerte que provoca el saldo cero, donde ha fracasado el principio de placer: primer sistema que intenta regular la excitación pulsional que se mueve en el eje displacer/placer, y también ha fracasado ése que le sucede en la tarea de regulador: el principio de realidad, que tampoco es capaz de domeñar por completo los movimientos de la pulsión que apuntan a un más allá del principio del placer. Con todo esto, esta economía política hace al sujeto vulnerable a un imperativo de goce, y esta vulnerabilidad se ve precisada por un fenómeno al que asistimos actualmente: el declive del registro simbólico entendido como límite al goce devenido por la función paterna; y el desvanecimiento del registro imaginario entendido como el manto que recubre lo real devenido por la función materna. Ambas funciones (materna y paterna) se han visto fallidas, en ocasiones inexistentes, y la lógica que va marcando la economía política del capitalismo va cooperando a su desaparición. Bajo esta lógica ahora se vuelve al origen, a lo nuclear, al eso, al ello, a lo real, a la cosificación del sujeto.

Podríamos enfocarnos en una visión fatalista del mundo, pensando en un infierno terrenal, un laberinto sin salida que lleva a la repetición del sufrimiento y la búsqueda de la destrucción; sin embargo, esta exposición de una problemática social no tiene por objeto mostrar un mundo convertido en cenizas, sino justamente una respuesta al autismo del discurso hipermoderno, porque el psicoanálisis no es autista a las problemáticas sociales. Con autismo nos referimos a una tendencia de la concentración en el mundo interior, el psicoanálisis no se presenta mudo, sino que, como lo expone Vilma Coccoz (2011), haciendo referencia a Freud: "El psicoanálisis es un saber nuevo para afrontar los temas atemporales, las últimas causas, los grandes problemas de la vida [...]", es por eso que primeramente es necesario exponer la problemática, exponer una interpretación de la realidad que está abrumando al sujeto y denigrándolo al nivel de la cosa, pero además una posición que muestre posibilidades de hacer frente a este fenómeno.

Así, llego a la última interrogante del presente ensayo: ¿qué puede hacerse ante la presencia de una economía que está saturando la existencia del sujeto? 
La posición del psicoanálisis es una posición que permite hacer frente al goce de la destrucción a través del sentido con la palabra. La solución apunta a que cada sujeto pueda desenvolverse mejor con su propio goce donde se vuelve necesaria la restauración de los límites, restauración a la que se accede haciendo un llamado a la función paterna y así, al registro simbólico que permite un límite al goce a través de la palabra. Como dice Lacan: "Si contra algo debemos luchar cada vez que tropezamos con lo que forma como un nudo en el trabajo del que se trata, el de la puesta a la luz del día por la vía del inconsciente, es contra la colusión de esta imagen con la idea de la satisfacción. Éste es el obstáculo, el límite o, mejor dicho, el engorro que hace que no atinemos y que nos quedemos encallados [...] (1969-1970: 31)". La apuesta del psicoanálisis es el reverso a esta imagen con la idea de satisfacción que esclaviza al sujeto, constituye el reverso a la globalización que empuja a esa pérdida de la subjetividad, así, también el reverso al capitalismo moderno que vende la idea de perfección. ¡No! Precisamente es esta idea la que justamente atora el trabajo vía el inconsciente en el psicoanálisis, porque es aquello que encierra al sujeto. Para el psicoanálisis no existe la perfección, no existe la felicidad absoluta, pero sí existe la posibilidad de encontrar ahí un sujeto en su propia subjetividad, apuntamos a sostener la opción de una vida digna, donde poner en regla al deseo y la pulsión del sujeto.

\section{Referencias}

Bentham, J. (1965). Escritos económicos. México, D.F.: Fondo de Cultura Económica.

Coccoz, V. (2011). Conferencia: El psicoanálisis: una ética para el siglo XXI. Recuperado de https://www.youtube.com/watch?v=K4uyXyTzpiM.

Freud, S. (2006). "Más allá del principio del placer". En Freud, Obras completas. Buenos Aires, Argentina: Amorrortu Editores. 
Lacan, J. (1969-1970). Seminario 17: El reverso del psicoanálisis. Buenos Aires-Barcelona-México: Ediciones Paidós.

Marx, K. (1968). Manuscritos económicos-filosóficos de 1844. México, D.F.: Editorial Grijalbo, S.A.

www.ucm.es/info/bas/biblioteca.htm.

www.icf-granada.net. 